\title{
Meta-analysis demonstrates association of XRCC1 genetic polymorphism Arg399Gln with esophageal cancer risk in the Chinese population
}

\author{
Z.Y. Zhang, Y. Xuan, X.Y. Jin, X. Tian and R. Wu \\ Department of Medical Oncology, Shengjing Hospital, \\ China Medical University, Shenyang, China \\ Corresponding author: Z.Y. Zhang \\ E-mail: cmuliangyuan@163.com
}

Genet. Mol. Res. 12 (3): 2567-2577 (2013)

Received July 23, 2012

Accepted November 10, 2012

Published January 16, 2013

DOI http://dx.doi.org/10.4238/2013.January.16.2

\begin{abstract}
We made a meta-analysis of the association between $\mathrm{X}$-ray cross-complementing gene 1 (XRCC1) genetic polymorphism Arg399Gln and esophageal cancer (EC) risk. Statistical analysis was performed with the Review Manager version 4.2.8 software program and STATA version 11.0. We selected 16 case-control studies for this meta-analysis, including 3591 EC cases and 5752 controls. Overall, the Gln399 allele was not associated with EC risk, compared with the Arg399 allele in the populations included in the analysis. However, stratified analysis revealed that the Gln399 allele was associated with increased EC risk among the Chinese population in a recessive model [odds ratio $(\mathrm{OR})=1.42 ; 95 \%$ confidence interval $(95 \% \mathrm{CI})=1.07-1.90$; $\mathrm{P}=0.02$ for heterogeneity $]$ and by homozygote contrast $(\mathrm{OR}=1.43$; $95 \% \mathrm{CI}=1.05-1.96 ; \mathrm{P}=0.02$ for heterogeneity), particularly for the tumor histology of squamous cell carcinoma $(\mathrm{OR}=1.46 ; 95 \% \mathrm{CI}=$ $1.10-1.95$ for the recessive model and $\mathrm{OR}=1.42 ; 95 \% \mathrm{CI}=1.03-1.95$ for the homozygote contrast). We conclude that the XRCC1 Arg399Gln
\end{abstract}


polymorphism has potential as a biomarker for EC susceptibility in the Chinese population, particularly for squamous cell carcinoma.

Key words: Esophageal cancer; Gene polymorphism; Meta-analysis; $\mathrm{X}$-ray cross-complementing gene 1

\section{INTRODUCTION}

Esophageal cancer (EC) is the eighth most commonly occurring cancer and the sixth most common cause of cancer-related death in the world, with the majority of cases occurring in developing countries (Parkin et al., 2005). Previous epidemiological studies demonstrated that nitrosamine carcinogens, cigarette smoking, alcohol drinking, and genetic polymorphisms might increase the risk of the disease (Gao et al., 1994; van Schooten et al., 1997; Yu et al., 2004). However, not all of those who have been exposed to the risk factors will develop EC, suggesting inter-individual differences in susceptibility. These differences may in part be caused by genetic variation, such as single nucleotide polymorphisms (SNPs) (Zienolddiny et al., 2006) in the DNA repair gene that increase susceptibility to DNA damage resulting from carcinogens, particularly when these SNPs are located within the coding or regulating regions causing altered protein expression.

One of the important DNA repair genes is the X-ray repair cross-complementing group 1 (XRCC1), mapped to chromosome 19q13.2-13.3 (Thompson et al., 1989; Thompson and West, 2000). The XRCC1 protein has no known catalytic activity but acts as a scaffolding protein for other base excision repair enzymes, including poly(ADP-ribose) polymerase, DNA polymerase- $\beta$, and DNA ligase III (Dianova et al., 2004). A G-to-A transition of the XRCC1 gene at codon 399 (Single Nucleotide Polymorphism Database No. rs25487) is located at the $\mathrm{COOH}$-terminal side of the poly(ADP-ribose) polymerase-interacting domain within a relatively nonconserved region between conserved residues of the BRCA1 C-terminus domain and leads to an amino acid substitution of Arg by Gln (Shen et al., 1998; Whitehouse et al., 2001). The presence of the variant $399 \mathrm{Gln}$ allele has been shown to correlate with DNA repair activity and one's susceptibility to various cancers (Goode et al., 2002).

Lee et al. (2001) first reported an association between XRCC1 polymorphisms and EC. Since the publication of this report, many studies have appeared in the literature either supporting or refuting the association. To clarify the effect of XRCC1 codon 399 polymorphisms on the risk of EC, we undertook a systematic review and meta-analysis.

\section{MATERIAL AND METHODS}

\section{Literature search strategy for study identification}

A comprehensive literature search was conducted using the PubMed, Springer, Elsevier, and CNKI (Chinese), and Wanfang (Chinese) Digital Dissertation databases for relevant articles published in any language up to January 2012 with key words "esophageal" or "esophagus" and "cancer", "neoplasm" or "carcinoma" combined with "XRCC1" or "X-ray repair cross-complementing group 1", "polymorphism" or "variant" and "Chinese", "China" or "orient". The full texts of the candidate articles were examined carefully to determine whether 
they were in accordance with the inclusion criteria for the meta-analysis. Besides the database search, the reference lists of the selected papers were also screened for other potential articles that may have been missed in the initial search.

The following criteria were used for the literature selection for the meta-analysis. 1) Studies that determined the distribution of the Arg399Gln genotype in patients with EC diagnosed by histopathologic biopsy and in controls free of cancer were eligible. 2) Only case-control studies were considered. 3) The paper needed to clearly describe EC diagnoses and the sources of cases and controls. 4) The authors had to offer the size of the sample, odds ratios (ORs) and their $95 \%$ confidence intervals $(95 \% \mathrm{CIs})$, or information that can help infer the results in the papers. 5) The definition of the exposure/risk genotypes was similar in all papers. 6) The methods of data collection and analysis had to be statistically acceptable. 7) Those publications that presented data allowing such outcomes to be derived were also included.

Accordingly, the following exclusion criteria were also used. 1) The design and the definition of the exposure were obviously different from those of the selected papers. 2) The source of cases and controls and other essential information were not provided. 3) Reviews and repeated studies were also excluded.

\section{Data extraction}

To minimize bias and improve reliability, 2 reviewers examined all potentially relevant studies independently. Data on the following characteristics were also extracted: first author, year of publication, distribution area, and number of genotyped patients and controls. The frequencies of the Gln allele were calculated for patients and controls from the corresponding genotype distributions.

\section{Meta-analysis}

The strength of the associations between EC and the XRCC1 Arg399Gln polymorphism was estimated using ORs with the corresponding 95\%CIs. For the Arg399Gln polymorphism, we first estimated the risk of the variant genotype $\mathrm{Gln} / \mathrm{Gln}$ compared with the wild-type Arg/Arg homozygote and then evaluated the risks of Gln/Gln vs (Arg/Gln + Arg/ Arg) and (Arg/Gln + Gln/Gln) vs Arg/Arg, which assumed the recessive and dominant effect of the variant $399 \mathrm{Gln}$ allele. In addition to the comparisons for all subjects, the studies were categorized into different subgroups according to ethnicity and histological type for further comparisons. In brief, the process consisted of the following steps:

1. Checking Hardy-Weinberg equilibrium (HWE): the Pearson $\chi^{2}$ test was used to determine whether the observed frequencies of genotypes conformed to the HWE (Schaid and Jacobsen, 1999).

2. Checking heterogeneity: heterogeneity, evaluated using the Cochrane Q-test among the studies, was considered to be significant at $\mathrm{P}<0.05$. The data were combined using both fixed- and random-effect models. Random effects are more appropriate when heterogeneity is present. Otherwise, the fixed-effect model is used for pooling (Zintzaras and Ioannidis, 2005).

3. Checking for publication bias: publication bias was assessed graphically by using funnel plots and assessed statistically using the Egger test (Egger et al., 1997).

All statistical analyses were performed with STATA 11.0 (StataCorp, College Station, TX, 
USA) and Review Manager, version 4.2.8 (Oxford, England, UK). All P values are two-sided.

\section{RESULTS}

\section{Eligible studies}

Twenty studies probing the relationship between the XRCC1 Arg399Gln polymorphism and EC susceptibility were identified. Four reports were excluded because the study designs were different from the others, i.e., they did not list data clearly enough for further analysis, or repeated studies. Sixteen eligible reports were judged to have met the inclusion criteria and provided complete data. The total sample size for the EC and control groups was 3591 and 5752, respectively. The characteristics of the studies included in the present meta-analysis are listed in Table 1.

\begin{tabular}{|c|c|c|c|c|c|c|c|c|c|c|c|c|}
\hline \multirow[t]{3}{*}{ Reference } & \multirow[t]{3}{*}{ Country } & \multirow[t]{3}{*}{ Ethnicity } & \multirow[t]{3}{*}{ Language } & \multirow[t]{3}{*}{ Method } & \multirow{3}{*}{$\begin{array}{l}\text { Cancer } \\
\text { type }\end{array}$} & \multicolumn{6}{|c|}{ XRCC1 condon 399} & \multirow[t]{3}{*}{ HWE } \\
\hline & & & & & & \multicolumn{3}{|c|}{ Esophageal cancer } & \multicolumn{3}{|c|}{ Control } & \\
\hline & & & & & & $\operatorname{Arg} / \operatorname{Arg}$ & $\mathrm{Arg} / \mathrm{Gln}$ & $\mathrm{Gln} / \mathrm{Gln}$ & $\operatorname{Arg} / \operatorname{Arg}$ & $\mathrm{Arg} / \mathrm{Gln}$ & $\mathrm{Gln} / \mathrm{Gln}$ & \\
\hline Lee et al., 2001 & China & Chinese & English & PCR-RFLP & ESCC & 64 & 33 & 8 & 132 & 108 & 24 & Yes \\
\hline Xing et al., 2002 & China & Chinese & English & PCR-RFLP & ESCC & 251 & 147 & 35 & 279 & 196 & 49 & Yes \\
\hline Yu et al., 2004 & China & Chinese & English & PCR-RFLP & ESCC & 66 & 51 & 19 & 88 & 59 & 5 & Yes \\
\hline Hao et al., 2004 & China & Chinese & English & PCR-RFLP & ESCC & 223 & 154 & 34 & 249 & 197 & 33 & Yes \\
\hline Ratnasinghe et al., 2004 & China & Chinese & English & Taqman & ESCC & 66 & 48 & 12 & 192 & 193 & 33 & Yes \\
\hline Casson et al., 2005 & Canada & Mixed & English & PCR-RFLP & EA & 18 & 28 & 10 & 25 & 47 & 23 & Yes \\
\hline Yin et al., 2005 & China & Chinese & Chinese & PCR-RFLP & ESCC & 66 & 26 & 14 & 65 & 37 & 4 & Yes \\
\hline Cai et al., 2006 & China & Chinese & English & PCR-RFLP & ESCC & 49 & 130 & 26 & 132 & 218 & 42 & No \\
\hline Ye et al., 2006 & Sweden & Caucasian & English & PCR-RFLP & $\mathrm{ESCC}+\mathrm{EA}$ & 73 & 83 & 21 & 179 & 244 & 49 & No \\
\hline Sobti et al., 2007 & India & Indian & English & PCR-RFLP & ESCC & 50 & 58 & 12 & 58 & 73 & 29 & Yes \\
\hline Liu et al., 2007 & USA & Mixed & English & PCR-RFLP & EA & 77 & 77 & 29 & 153 & 142 & 41 & Yes \\
\hline Tse et al., 2008 & USA & Mixed & English & Taqman & EA & 136 & 133 & 42 & 216 & 182 & 54 & Yes \\
\hline Ferguson et al., 2008 & Ireland & Caucasian & English & Taqman & EA & 84 & 99 & 26 & 100 & 115 & 33 & Yes \\
\hline Zhao et al., 2010 & China & Chinese & Chinese & PCR-RFLP & ESCC & 105 & 71 & 26 & 171 & 126 & 20 & Yes \\
\hline Yu et al., 2011 & China & Chinese & English & PCR-RFLP & ESCC & 237 & 156 & 39 & 536 & 331 & 48 & Yes \\
\hline Yun, 2011 & China & Chinese & Chinese & PCR-RFLP & $\mathrm{ESCC}+\mathrm{EA}$ & 184 & 166 & 29 & 223 & 169 & 30 & Yes \\
\hline
\end{tabular}

$\mathrm{EA}=$ esophageal adenocarcinoma; $\mathrm{ESCC}=$ esophageal squamous cell carcinoma; PCR-RFLP = polymerase chain reaction-restriction fragment length polymorphism; HWE $=$ Hardy-Weinberg equilibrium.

In terms of histology, 4 studies investigated esophageal adenocarcinoma (EA), 10 investigated esophageal squamous cell carcinoma (ESCC) and 2 investigated both EA and ESCC. Twelve studies indicated that the frequency distributions of genotypes in the cases and controls were consistent with HWE, whereas 1 study from Sweden showed significant deviation from HWE (Ye et al., 2006). Since 3 other studies did not provide HWE information (Lee et al., 2001; Ratnasinghe 2004; Cai et al., 2006), we calculated the expected distribution using the observed data and found that 1 study significantly deviated from HWE (cases: $\chi^{2}=16.59, \mathrm{P}<0.001$; controls: $\left.\chi^{2}=11.89, \mathrm{P}<0.001\right)(\mathrm{Cai}$ et al., 2006). As for quality control of genotyping, all studies obtained DNA from peripheral blood, a classical polymerase chain reaction-restriction fragment length polymorphism assay was used in $13(81 \%)$ of the studies, and the rest used TaqMan allelic discrimination assay. 


\section{Effects of XRCC1 Arg399Gln on EC risk}

Individuals carrying the variant homozygous genotype Gln/Gln of codon 399 were not significantly associated with increased risk to EC compared with the individuals with the wild-type homozygous genotype $\mathrm{Arg} / \mathrm{Arg}(\mathrm{OR}=1.22 ; 95 \% \mathrm{CI}=0.97-1.54 ; \mathrm{P}=0.08)$, although 4 studies (Yin et al., 2005; Zhao et al., 2010; Yu et al., 2004, 2011) demonstrated a significantly increased risk (Figure 1). Similarly, no statistically significant associations were found with recessive and dominant modeling (Gln/Gln vs $\mathrm{Arg} / \mathrm{Gln}+\mathrm{Arg} / \mathrm{Arg}, \mathrm{OR}=$ $1.22,95 \% \mathrm{CI}=0.99-1.50, \mathrm{P}=0.07 ; \mathrm{Arg} / \mathrm{Gln}+\mathrm{Gln} / \mathrm{Gln}$ vs $\mathrm{Arg} / \mathrm{Arg}, \mathrm{OR}=1.02,95 \% \mathrm{CI}=$ $0.91-1.14, \mathrm{P}=0.77)$.

\begin{tabular}{|c|c|c|c|c|c|c|}
\hline $\begin{array}{l}\text { Review: } \\
\text { Comparison: } \\
\text { Outcome: }\end{array}$ & $\begin{array}{l}\text { Arg399Gin } \\
\text { sm Arg399G } \\
\text { en XRCC1 po }\end{array}$ & g399Gin and & & \multirow[b]{2}{*}{$\begin{array}{c}\text { Weight } \\
\%\end{array}$} & & \\
\hline $\begin{array}{l}\text { Study } \\
\text { or sub-category }\end{array}$ & $\begin{array}{l}\text { Case } \\
\mathrm{MN}\end{array}$ & $\begin{array}{c}\text { Control } \\
n / N\end{array}$ & $\begin{array}{l}\text { OR (random) } \\
95 \% \mathrm{Cl}\end{array}$ & & \multicolumn{2}{|r|}{$\begin{array}{c}\text { OR (random) } \\
95 \% \mathrm{Cl}\end{array}$} \\
\hline \multicolumn{7}{|c|}{$01 \mathrm{Gm} / \mathrm{Gh}$ versus $\mathrm{Arg} / \mathrm{Arg}$} \\
\hline Lee 2001 & $8 / 72$ & $24 / 156$ & 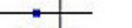 & 1.05 & 0.69 & {$[0.29,1.62]$} \\
\hline Xing 2002 & $35 / 286$ & $49 / 328$ & & 2.35 & 0.79 & $(0.50,1.27)$ \\
\hline Hao 2004 & $34 / 257$ & $33 / 282$ & $-\infty$ & 2.12 & 1.15 & {$[0.69,1.92]$} \\
\hline Ratnasinghe 200 & $12 / 78$ & $33 / 225$ & - & 1.37 & 1.06 & $(0.52,2.17]$ \\
\hline Yu 2004 & $19 / 85$ & $5 / 93$ & & 0.77 & 5.07 & $(1.80,14.27\}$ \\
\hline Casson 2005 & $10 / 28$ & $23 / 48$ & - & 0.88 & 0.60 & $10.23,1.571$ \\
\hline Yin 2005 & $14 / 80$ & $4 / 69$ & & 0.63 & 3.45 & {$[1.08,11.03\}$} \\
\hline Cai 2006 & $26 / 75$ & $42 / 174$ & 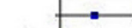 & 1.79 & 1.67 & {$[0.93,3.00]$} \\
\hline Ye 2006 & $21 / 94$ & $49 / 228$ & $=$ & 1.83 & 1.05 & $(0.59,1.88]$ \\
\hline Liv 2007 & $29 / 106$ & $41 / 194$ & 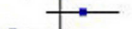 & 1.95 & 1.41 & {$[0.81,2.43]$} \\
\hline Sobti 2007 & $12 / 62$ & $29 / 87$ & & 1.23 & 0.48 & {$[0.22,1.04]$} \\
\hline Ferguson 2008 & $26 / 110$ & $33 / 133$ & - & 1.79 & 0.94 & {$[0.52,1.69]$} \\
\hline Tse 2008 & $42 / 178$ & $54 / 270$ & - & 2.40 & 1.24 & {$[0.78,1.95]$} \\
\hline Zhao 2010 & $26 / 131$ & $20 / 191$ & & 1.64 & 2.12 & $(1.13,3.98]$ \\
\hline Yu 2011 & $39 / 276$ & $48 / 584$ & $\longrightarrow$ & 2.44 & 1.84 & {$[1.17,2.88]$} \\
\hline Yun 2011 & $29 / 213$ & $30 / 253$ & 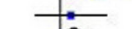 & 1.96 & 1.27 & $10.68,2.021$ \\
\hline & & 3315 & & 26.20 & 1.22 & {$[0.97,1.54]$} \\
\hline \multicolumn{7}{|c|}{$\begin{array}{l}\text { Total events: } 382 \text { (Case), } \$ 17 \text { (Control) } \\
\text { Test for heterogenety: Chi }{ }^{2}=31.70, \text { dff. }=15(P=0.007), 1^{2}=52.7 \% \\
\text { Test for overall effect: } Z=1.73(P=0.08)\end{array}$} \\
\hline
\end{tabular}

Figure 1. Meta-analysis of esophageal cancer associated with XRCC1 codon 399 genotypes in a homozygote model. For each study, the estimates of odds ratio (OR) and its $95 \%$ confidence interval $(95 \% \mathrm{CI})$ were plotted with a box and a horizontal line. d.f. $=$ degrees of freedom.

\section{XRCC1 Arg399GIn and EC risk by ethnicity}

We performed a stratified analysis by ethnicity and histology type. We noticed that the frequencies of the Arg or Gln allele among Asians and Caucasians varied $(\mathrm{Hu}$ et al., 2005). Since there was only one study on Indians (Sobti et al., 2007) in our metaanalysis, we just divided the studies into Chinese and Caucasians. Because some studies did not clearly define the ethnicity of their study populations, we assumed the studies conducted in Western countries without ethnic specification as "Caucasians". In Chinese subjects, the XRCC1 Gln/Gln genotype was significantly associated with an increased risk of EC in a homozygote comparison (Gln/Gln $v s \mathrm{Arg} / \mathrm{Arg}$ : $\mathrm{OR}=1.43 ; 95 \% \mathrm{CI}=1.05$ 1.96; $\mathrm{P}=0.02$ for heterogeneity) and in a recessive model (Gln/Gln vs Arg/Arg + Arg/ Gln: $\mathrm{OR}=1.42 ; 95 \% \mathrm{CI}=1.07-1.90 ; \mathrm{P}=0.02$ for heterogeneity) (Figure 2 ) but not in a dominant model $(\mathrm{Gln} / \mathrm{Gln}+\mathrm{Arg} / \mathrm{Gln} v s \mathrm{Arg} / \mathrm{Arg}: \mathrm{OR}=1.03 ; 95 \% \mathrm{CI}=0.88-1.20 ; \mathrm{P}=0.74$ 
Arg399Gln SNP and EC risk in either ESCC or EA, but showed substantial heterogeneity among the 11 studies of ESCC $(\mathrm{P}=0.002)$ (Table 2). To identify the source of heterogeneity, we excluded the study by Cai et al. (2006) and the Swedish study (Ye et al., 2006), which showed a significant HWE deviation of the XRCC1 Arg399Gln; however, both of the results showed an even increased heterogeneity $(\mathrm{P}=0.001)$. There was one study from North India that showed some protective effect of the XRCC1 Gln/Gln genotype among drinkers. After we excluded this Indian study, the heterogeneity decreased, and there appeared a significant association between the XRCC1 Gln allele and risk of ESCC in either a homozygote comparison $(\mathrm{Gln} / \mathrm{Gln} v \mathrm{~s} \mathrm{Arg} / \mathrm{Arg}$ : $\mathrm{OR}=1.42 ; 95 \% \mathrm{CI}=1.03-1.95$; $\mathrm{P}=0.009$ for heterogeneity) or a recessive model (Gln/Gln $v s \mathrm{Arg} / \mathrm{Arg}+\mathrm{Arg} / \mathrm{Gln}: \mathrm{OR}=$ $1.46 ; 95 \% \mathrm{CI}=1.10-1.95 ; \mathrm{P}=0.03$ for heterogeneity) (Figure 3 ).

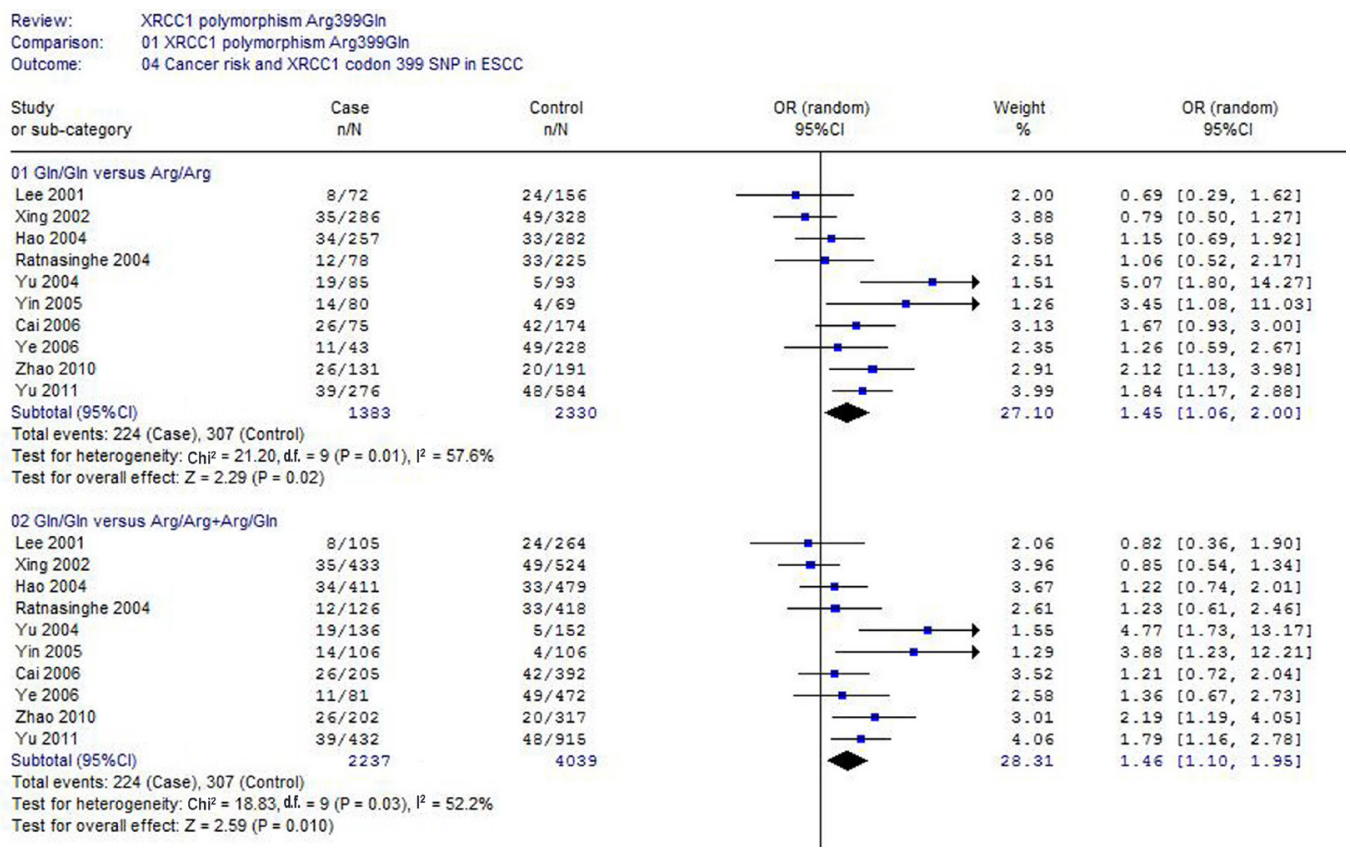

Figure 3. Meta-analysis of esophageal cancer associated with XRCC1 codon 399 genotypes in homozygote and recessive models in squamous cell carcinoma, after excluding the study from India. For each study, the estimates of odds ratio $(\mathrm{OR})$ and its $95 \%$ confidence interval $(95 \% \mathrm{CI})$ were plotted with a box and a horizontal line. d.f. $=$ degrees of freedom.

\section{Publication bias}

Because the shape of the funnel plot appeared to be symmetric (Figure 4) and the Egger regression test results were not significant $(\mathrm{t}=-0.08, \mathrm{P}=0.934)$, publication biases might not have had a significant influence on the results of the XRCC1 gene. 


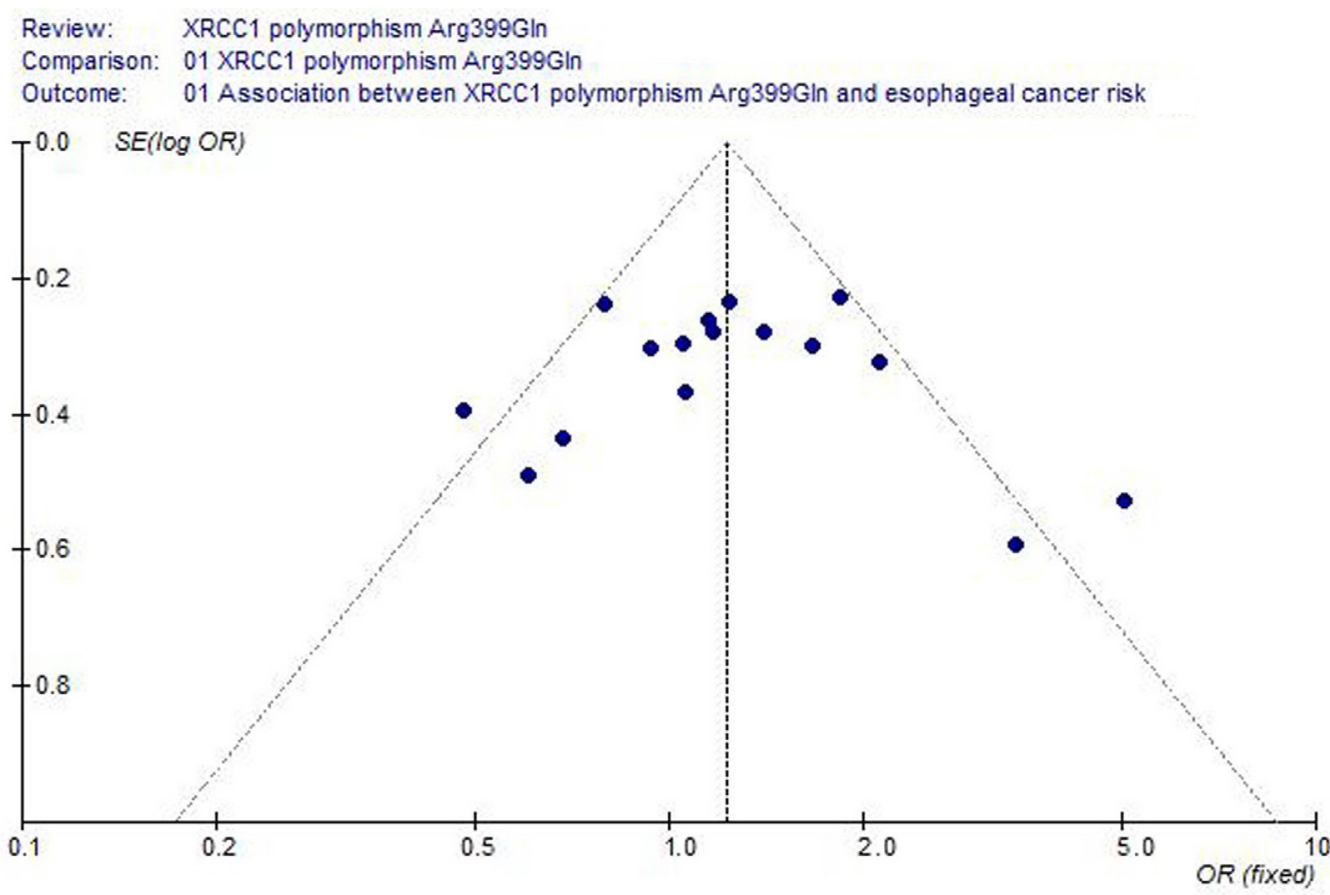

Figure 4. Funnel plot analysis to detect publication bias. Each point represents a separate study for the indicated association. $\mathrm{SE}=$ standard error; $\mathrm{OR}=$ odds ratio.

\section{DISCUSSION}

Our meta-analysis summarized the evidence to date regarding the association between the XRCC1 Arg399Gln polymorphism and EC, involving a pooled total of 3591 patients with EC and 5752 controls from 16 studies. The overall data showed that the XRCC1 Arg399Gln polymorphism is unlikely to be a major risk factor for EC susceptibility in a wide population. However, on subgroup analysis, our results indicated that the XRCC1 Arg399Gln polymorphism was significantly associated with EC in Chinese subjects, particularly for ESCC.

Previous studies have found that the XRCC1 399Gln/Gln genotype is associated with a risk of lung cancer among Asians (Kiyohara et al., 2006) and breast cancer in African Americans (Duell et al., 2001), which also found an ethnic difference of the Gln399 allele with cancer susceptibility. If the association between this polymorphism and EC holds true, especially in Chinese subjects, this may be because of gene-to-gene or gene-to-environment interactions, or it may be a reflection of a pattern of linkage disequilibrium with other more important polymorphisms, unique to men of Chinese background. However, it is still hard to claim the association between the Gln399 allele and EC risk in Chinese due to the currently limited data, and further studies in Chinese may be required in the future.

Our analysis also demonstrated that the XRCC1 Gln399 allele elevated risk of ESCC in Chinese, which is inconsistent with the study of Dai et al. (2009). The different results may be due to the studies performed in the last 3 years and included in our meta-analysis. However, the lack 
of effect of the Gln399 allele on EA may be explained by different patterns of genetic alterations and gene-environment interactions. Our data also suggested that the study from the North Indian population should be considered separately, because it caused significant between-study heterogeneity in the analysis of ESCC. In that study, the XRCC1 Gln/Gln genotype protected Indian drinkers from EC, but the underlying mechanisms remain unclear (Sobti et al., 2007).

Our analysis did not evaluate whether the XRCC1 Arg399Gln polymorphism may affect the clinical behavior of EC or other clinicopathologic attributes because of the lack of sufficient studies. However, 2 studies did generate some relevant data. Liu et al. (2006) claimed that ESCC patients with 399 wild type had a high metastastic rate, and that XRCC1 Arg399Gln was associated with ESCC TNM stage and lymph node metastasis, both of which affected the prognosis of ESCC. Another study (Zhang et al., 2010) showed that there was a significant correlation between the radiosensitivity and polymorphisms of XRCC1 Arg$399 \mathrm{Gln}$. The response rates of radiotherapy for XRCC1 Arg/Arg, Arg/Gln, Gln/Gln genotypes were $91.5,88.9$ and $60.0 \%$, respectively $(\mathrm{P}=0.009)$.

In the present meta-analysis, we searched as many publications that had been carried out in the Chinese population as we could. The most of the published studies with full text that we searched were in English or Chinese, and we believe that most of the related literature was obtained and screened in our study. Furthermore, we performed a test of heterogeneity and examined the sources of heterogeneity, and publication bias was not observed in the analysis of funnel plots and the Egger test. The results of our meta-analysis could be considered accurate and valid. However, there are still some limitations inherited from the published studies. First, selection bias could have influenced our analysis of Caucasian populations since we assumed that the subjects were Caucasian in studies conducted in Western countries. In addition, the genotype distribution of the Arg399Gln polymorphism among control subjects did not conform to HWE in 2 studies (Cai et al., 2006; Ye et al., 2006). Second, in our collection process, unpublished studies, index words, search area, and language all could have produced biases. Third, confounding factors might have had an impact on the conclusion of our study because of case-control studies. For instance, some studies used a healthy population as the reference group, whereas others selected hospital patients without organic esophageal diseases as the reference group, which might have influenced the meta-analysis results because the hospital controls were more likely to develop EC in the future. Therefore, larger studies with different ethnic populations and tumor histology are needed to clarify the possible roles of XRCC1 polymorphisms in the etiology of EC.

\section{CONCLUSIONS}

In summary, our meta-analysis revealed that the XRCC1 Arg399Gln polymorphism did not alter susceptibility to $\mathrm{EC}$ in the overall populations, whereas there was evidence for an association between the XRCC1 Gln399 variant allele and increased EC risk under the homozygote contrast and a recessive model among Chinese populations, particularly for ESCC. This warrants additional investigations in larger studies and meta-analysis to clarify the possible roles of the XRCC1 Arg399Gln polymorphism in the etiology of EC.

\section{REFERENCES}

Cai L, You NC, Lu H, Mu LN, et al. (2006). Dietary selenium intake, aldehyde dehydrogenase-2 and X-ray repair crosscomplementing 1 genetic polymorphisms, and the risk of esophageal squamous cell carcinoma. Cancer 106: 2345-2354. 
Casson AG, Zheng Z, Evans SC, Veugelers PJ, et al. (2005). Polymorphisms in DNA repair genes in the molecular pathogenesis of esophageal (Barrett) adenocarcinoma. Carcinogenesis 26: 1536-1541.

Dai L, Wang K, Zhang J, Lv Q, et al. (2009). XRCC1 gene polymorphisms and esophageal squamous cell carcinoma risk in Chinese population: A meta-analysis of case-control studies. Int. J. Cancer 125: 1102-1109.

Dianova II, Sleeth KM, Allinson SL, Parsons JL, et al. (2004). XRCC1-DNA polymerase beta interaction is required for efficient base excision repair. Nucleic Acids Res. 32: 2550-2555.

Duell EJ, Millikan RC, Pittman GS, Winkel S, et al. (2001). Polymorphisms in the DNA repair gene XRCC1 and breast cancer. Cancer Epidemiol. Biomarkers Prev. 10: 217-222.

Egger M, Davey Smith G, Schneider M and Minder C (1997). Bias in meta-analysis detected by a simple, graphical test. BMJ 315: 629-634.

Ferguson HR, Wild CP, Anderson LA, Murphy SJ, et al. (2008). No association between hOGG1, XRCC1, and XPD polymorphisms and risk of reflux esophagitis, Barrett's esophagus, or esophageal adenocarcinoma: results from the factors influencing the Barrett's adenocarcinoma relationship case-control study. Cancer Epidemiol. Biomarkers Prev. 17: 736-739.

Gao YT, McLaughlin JK, Blot WJ, Ji BT, et al. (1994). Risk factors for esophageal cancer in Shanghai, China. I. Role of cigarette smoking and alcohol drinking. Int. J. Cancer 58: 192-196.

Goode EL, Ulrich CM and Potter JD (2002). Polymorphisms in DNA repair genes and associations with cancer risk. Cancer Epidemiol. Biomarkers Prev. 11: 1513-1530.

Hao B, Wang H, Zhou K, Li Y, et al. (2004). Identification of genetic variants in base excision repair pathway and their associations with risk of esophageal squamous cell carcinoma. Cancer Res. 64: 4378-4384.

$\mathrm{Hu} \mathrm{Z}$, Ma H, Chen F, Wei Q, et al. (2005). XRCC1 polymorphisms and cancer risk: a meta-analysis of 38 case-control studies. Cancer Epidemiol. Biomarkers Prev. 14: 1810-1818.

Kiyohara C, Takayama K and Nakanishi Y (2006). Association of genetic polymorphisms in the base excision repair pathway with lung cancer risk: a meta-analysis. Lung Cancer 54: 267-283.

Lee JM, Lee YC, Yang SY, Yang PW, et al. (2001). Genetic polymorphisms of XRCC1 and risk of the esophageal cancer. Int. J. Cancer 95: 240-246.

Liu G, Zhou W, Yeap BY, Su L, et al. (2007). XRCC1 and XPD polymorphisms and esophageal adenocarcinoma risk. Carcinogenesis 28: 1254-1258.

Liu JW, Lei W, Ma JX and Xue RG (2006). The relationship between polymorphism in XRCC1 and TNM staging and lymph node metastasis of esophageal squamous cell carcinoma. Chin. J. Thorac. Cardiovasc. Surg. 22: 315-317.

Parkin DM, Bray F, Ferlay J and Pisani P (2005). Global cancer statistics, 2002. CA Cancer J. Clin. 55: 74-108.

Ratnasinghe LD, Abnet C, Qiao YL, Modali R, et al. (2004). Polymorphisms of XRCC1 and risk of esophageal and gastric cardia cancer. Cancer Lett. 216: 157-164.

Schaid DJ and Jacobsen SJ (1999). Biased tests of association: comparisons of allele frequencies when departing from Hardy-Weinberg proportions. Am. J. Epidemiol. 149: 706-711.

Shen MR, Jones IM and Mohrenweiser H (1998). Nonconservative amino acid substitution variants exist at polymorphic frequency in DNA repair genes in healthy humans. Cancer Res. 58: 604-608.

Sobti RC, Singh J, Kaur P, Pachouri SS, et al. (2007). XRCC1 codon 399 and ERCC2 codon 751 polymorphism, smoking, and drinking and risk of esophageal squamous cell carcinoma in a North Indian population. Cancer Genet. Cytogenet. 175: 91-97.

Thompson LH and West MG (2000). XRCC1 keeps DNA from getting stranded. Mutat. Res. 459: 1-18.

Thompson LH, Bachinski LL, Stallings RL, Dolf G, et al. (1989). Complementation of repair gene mutations on the hemizygous chromosome 9 in CHO: a third repair gene on human chromosome 19. Genomics 5: 670-679.

Tse D, Zhai R, Zhou W, Heist RS, et al. (2008). Polymorphisms of the NER pathway genes, ERCC1 and XPD are associated with esophageal adenocarcinoma risk. Cancer Causes Control 19: 1077-1083.

van Schooten FJ, Godschalk RW, Breedijk A, Maas LM, et al. (1997). ${ }^{32} \mathrm{P}-$ postlabelling of aromatic DNA adducts in white blood cells and alveolar macrophages of smokers: saturation at high exposures. Mutat. Res. 378: 65-75.

Whitehouse CJ, Taylor RM, Thistlethwaite A, Zhang H, et al. (2001). XRCC1 stimulates human polynucleotide kinase activity at damaged DNA termini and accelerates DNA single-strand break repair. Cell 104: 107-117.

Xing D, Tan W, Wei Q and Lin D (2002). Polymorphisms of the DNA repair gene XPD and risk of lung cancer in a Chinese population. Lung Cancer 38: 123-129.

Ye W, Kumar R, Bacova G, Lagergren J, et al. (2006). The XPD 751Gln allele is associated with an increased risk for esophageal adenocarcinoma: a population-based case-control study in Sweden. Carcinogenesis 27: 1835-1841.

Yin LH, Pu YP, Song YH, Hu X, et al. (2005). Polymorphisms of susceptible genes for esophageal cancer risk in Huaian population in Jiangsu province. Tumor 25: 357-361.

Yu H, Fu C, Wang J, Xue H, et al. (2011). Interaction between XRCC1 polymorphisms and intake of long-term stored rice 
in the risk of esophageal squamous cell carcinoma: a case-control study. Biomed. Environ. Sci. 24: 268-274.

Yu HP, Zhang XY, Wang XL, Shi LY, et al. (2004). DNA repair gene XRCC1 polymorphisms, smoking, and esophageal cancer risk. Cancer Detect. Prev. 28: 194-199.

Yun YX (2011). XRCC1 Gene Polymorphisms and Susceptibility to Developing Esophageal Cancer in Henan Han Population. Available at [http://d.g.wanfangdata.com.cn/ Thesis_Y 1929988.aspx]. Accessed May 2011.

Zhang XS, Aheli-Nasiroula, Zhang JR, Lv Y, et al. (2010). Association study on single nucleotide polymorphism in hOGG 1, XRCC 1, XRCC3 and radiosensitivity in esophageal cancer. J. XinJiang Med. Univ. 33: 473-481.

Zhao WP, Lu P, Miao ZH and Xu F (2010). Correlation of XRCC1 Codon 399 Polymorphisms and Risk of Esophageal Squamous Cell Carcinoma in North HeNan population. Med. Info. 3: 470-472.

Zienolddiny S, Campa D, Lind H, Ryberg D, et al. (2006). Polymorphisms of DNA repair genes and risk of non-small cell lung cancer. Carcinogenesis 27: 560-567.

Zintzaras E and Ioannidis JP (2005). Heterogeneity testing in meta-analysis of genome searches. Genet. Epidemiol. 28: 123-137. 